\title{
HPLC-FLD Simultaneous Determination of 13 Polycyclic Aromatic Hydrocarbons: Validation of an Analytical Procedure for Soybean Oils
}

\author{
Mônica C. R. Camargo, ${ }^{* a}$ Paula R. Antoniolli ${ }^{b}$ and Eduardo Vicente ${ }^{a}$ \\ ${ }^{a}$ Centro de Ciência e Qualidade de Alimentos, Instituto de Tecnologia de Alimentos, \\ Av. Brasil, 2880, 13070-178 Campinas-SP, Brazil
}

${ }^{b}$ Instituto de Química, Universidade Estadual de Campinas, 13083-970 Campinas-SP, Brazil

\begin{abstract}
Um método usando cromatografia líquida de alta eficiência com detecção por fluorescência (HPLC-FLD) foi desenvolvido para a determinação simultânea de 13 hidrocarbonetos policíclicos aromáticos (HPAs) em óleos de soja. A preparação das amostras envolve etapas de extração líquidolíquido com dimetilformamida-água $(9: 1 \mathrm{v} / \mathrm{v})$, seguida de extração e pré-concentração dos HPAs em fase sólida utilizando cartuchos C-18. O método apresentou bons níveis de recuperação para a maioria dos HPAs estudados com valores entre 71 e 115\%. As curvas de calibração obtidas se mostraram lineares dentro das respectivas faixas de trabalho $\left(\mathrm{R}^{2}>0,999\right)$. Os limites de detecção (LOD) e quantificação (LOQ) variaram entre $0,02-0,76 \mu \mathrm{g} \mathrm{kg}^{-1}$ e $0,03-0,96 \mu \mathrm{g} \mathrm{kg}^{-1}$, respectivamente. O método foi aplicado para avaliar a contaminação dos óleos de soja comerciais mais consumidos no mercado brasileiro. A presença de HPAs foi confirmada em todas as amostras analisadas com valores médios na faixa de 0,20 a $5,93 \mu \mathrm{g} \mathrm{kg}^{-1}$.
\end{abstract}

A method using high performance liquid chromatography with fluorescence detection (HPLC-FLD) was developed for the simultaneous determination of 13 polycyclic aromatic hydrocarbons (PAHs) in soybean oils. The sample preparation includes liquid-liquid extraction with dimethylformamide-water (9:1, v/v) followed by a clean-up and concentration step with C-18 SPE cartridges. The method showed good recoveries for most of the PAHs studied with values between 71 and $115 \%$. The calibration curves were linear over the range tested $\left(\mathrm{R}^{2}>0.999\right)$. Detection and quantification limits varied between $0.02-0.76 \mu \mathrm{g} \mathrm{kg}^{-1}$ and $0.03-0.96 \mu \mathrm{g} \mathrm{kg}^{-1}$, respectively. The analytical procedure was successfully applied to evaluate the contamination of most consumed brands of soybean oils commercially available in the Brazilian market. The presence of PAHs was confirmed in all samples analyzed with mean values ranging from 0.20 to $5.93 \mu \mathrm{g} \mathrm{kg}^{-1}$.

Keywords: polycyclic aromatic hydrocarbons (PAHs), soybean oils, HPLC-fluorescence, organic contaminants, food analysis

\section{Introduction}

The occurrence of polycyclic aromatic hydrocarbons (PAHs) in food has attracted so much attention in the last few years because it is directly related to food safety. PAHs represent an important class of chemical carcinogens formed during incomplete combustion of organic material. Food is a significant source of PAHs for which human are exposed and their presence originate predominately from environmental pollution, during food processing (drying and smoking) and cooking (grilling, roasting, frying etc). ${ }^{1}$ Thus, variable levels of PAHs have been reported in different food categories and

*e-mail: monicarojo@uol.com.br beverages including vegetables and fruits, cereals, oils and fats, smoked products, coffee and tea. ${ }^{2-12}$

PAHs were evaluated by the International Programme on Chemical Safety (IPCS), the Scientific Committee on Food (SCF) and by the Joint FAO/WHO Expert Committee on Food Additives (JECFA). SCF concluded that 15 PAHs namely benzo[a]anthracene, benzo[b]fluoranthene, benzo[j]fluoranthene, benzo[ $k]$ fluoranthene, benzo[ $\mathrm{ghi}]$ perylene, benzo[a]pyrene, chrysene, cyclopenta $[c d]$ pyrene, dibenzo[ $a, h]$ anthracene, dibenzo[a,e]pyrene, dibenzo[ $[a, h]$ pyrene, dibenzo[ $[a, i]$ pyrene, dibenzo $[a, l]$ pyrene, indeno[1,2,3-cd]pyrene and 5-methylchrysene, show clear evidence of mutagenicity/genotoxicity in somatic cells in experimental animals in vivo and, with 
the exception of benzo[ghi]perylene, have also shown clear carcinogenic effects in various types of bioassays in experimental animals. ${ }^{13}$ During the JECFA sixty fourth meeting in 2005, the IPCS assessments and SCF re-evaluation of 33 compounds pointed the conclusion that 13 PAHs were clearly carcinogenic and genotoxic (Figure 1). ${ }^{1}$ Except for benzo[ $[g h i]$ perylene and cyclopenta $[c d]$ pyrene, the compounds were the same as those stated by SCF.,13

Studies conducted in Brazil and in many other countries have identified specific food categories as important sources of human exposure to PAHs, highlighting the oil and fat group. ${ }^{3,4,11,14-18}$ The presence of polycyclic aromatic hydrocarbons in vegetable oils may be attributed to (i) atmospheric contamination of plant material, (ii) direct drying of the plant material with combustion smoke before extraction, (iii) contamination through the solvent extraction and (iv) uptake by the oil plants from contaminated soils., ${ }^{2,14}$ During the refining processes, the concentrations of these contaminants can be drastically reduced. The deodorization step contributes to remove mainly light PAHs (up to four aromatic rings), while charcoal treatment is responsible to reduce the heavy ones ( 5 and more aromatic rings). ${ }^{2,19,20}$ Nevertheless, in Brazil the use of charcoal as adsorbent by the oil refineries is not a common practice and, in addition, the Brazilian regulation for oils and fats does not establish a maximum level for any PAH.

In this context it is necessary that rapid and reliable methods are available for monitoring the levels of these compounds in different matrices. The analytical

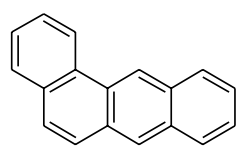

benzo(a)anthracene $\left(\mathrm{C}_{18} \mathrm{H}_{12}\right)$

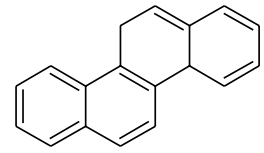

chrysene $\left(\mathrm{C}_{18} \mathrm{H}_{12}\right)$

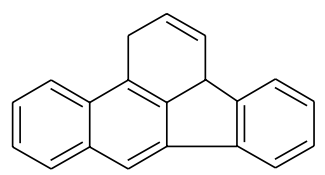

benzo(b)fluoranthene $\left(\mathrm{C}_{20} \mathrm{H}_{12}\right)$

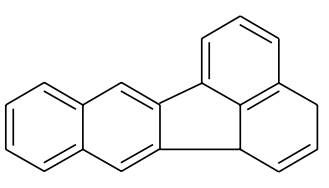

benzo(k)fluoranthene $\left(\mathrm{C}_{20} \mathrm{H}_{12}\right)$

procedures mostly used for PAHs involve several steps with an extensive clean-up and require large volumes of organic solvents. ${ }^{2,11,18,21-23}$ Solid-phase extraction (SPE) has been successfully applied, showing good selectivity and recovery, requiring smaller amounts of solvent for elution and resulting in shorter time analysis. ${ }^{23-25}$

Although several methods for different sets of PAHs have been described in the literature, no one has designed for a simultaneous HPLC determination of the 13 PAHs, considered genotoxic and carcinogenic by the JECFA, in edible oils. The committee stated that the major analytical methods developed do not include most dibenzopyrenes and 5-methyl-chrysene and recommended the development of methods in order to include these compounds. ${ }^{1}$

Thus, the aim of this study was to establish a method to separate and quantify the compounds highlighted by the JECFA in soybean oils by reversed-phase high performance liquid chromatography with fluorescence detection, using SPE during sample preparation. The validated method was then applied to evaluate the levels of PAHs in the most consumed brands of soybean oils commercially available in the Brazilian market.

\section{Experimental}

\section{Chemicals and reagents}

PAH standards were purchased from: Supelco Inc. (USA) (benzo $[a]$ anthracene, chrysene, benzo[ $[b]$ fluoranthene,<smiles>Cc1cc2ccccc2c2c1C1C=CC=CC1=CC2</smiles>

5-methyl chrysene $\left(\mathrm{C}_{19} \mathrm{H}_{14}\right)$<smiles></smiles>

benzo(a)pyrene $\left(\mathrm{C}_{20} \mathrm{H}_{12}\right)$<smiles></smiles>

benzo(j)fluoranthene $\left(\mathrm{C}_{20} \mathrm{H}_{12}\right)$<smiles></smiles>

dibenzo(al)pyrene $\left(\mathrm{C}_{24} \mathrm{H}_{14}\right)$<smiles>C1=CCc2c(ccc3c2=CC2=CCc4ccccc4C2C=3)C1</smiles>

dibenzo(ah)anthracene $\left(\mathrm{C}_{22} \mathrm{H}_{14}\right)$

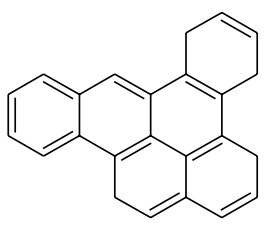

dibenzo(ae)pyrene $\left(\mathrm{C}_{24} \mathrm{H}_{14}\right)$

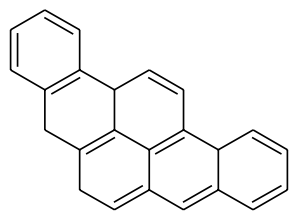

dibenzo(ai)pyrene $\left(\mathrm{C}_{24} \mathrm{H}_{14}\right)$

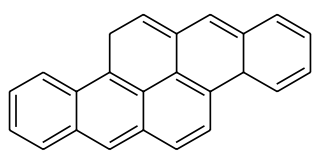

dibenzo(ah)pyrene $\left(\mathrm{C}_{24} \mathrm{H}_{14}\right)$

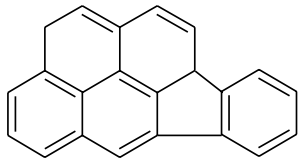

indeno 123 cd-pyrene $\left(\mathrm{C}_{22} \mathrm{H}_{12}\right)$

Figure 1. Structure, name and molecular formula of PAHs. 
benzo $[k]$ fluoranthene, benzo $[a]$ pyrene, dibenzo $[a h]$ anthracene and indeno[1,2,3-cd]pyrene), Fluka (USA) (benzo[j]fluoranthene, dibenzo[ $[a l]$ pyrene, dibenzo[ae]pyrene and dibenzo[ah]pyrene), Cambridge Isotope Laboratories Inc. (USA) (5-methyl-chrysene) and ChemService Inc. (USA) (dibenzo[ai]pyrene). The purities of the standards varied from 98.3 to $99.9 \%$. Cyclohexane, hexane, $\mathrm{N}, \mathrm{N}$-dimethylformamide, methanol and acetonitrile, all of analytical grade or higher, were acquired from J.T. Baker (Mexico). Ultrapure water was obtained from a Milli-Q water purification system (Millipore, Bedford, MA, USA).

\section{Oil samples}

Samples of commercial soybean oil were acquired from supermarkets in the metropolitan area of Campinas-SP (Brazil) in the years of 2007 and 2008. Four batches of three different brands of soybean oil, totalizing 24 samples, were analyzed in duplicate. These samples covered the most consumed brands with at least $90 \%$ market share of the soybean oil sold in the region.

\section{Sample preparation}

A sample of soybean oil $(0.5 \mathrm{~g})$ was dissolved in $5 \mathrm{~mL}$ of hexane and the mixture was extracted twice with $5 \mathrm{~mL}$ of $N, N$-dimethylformamide-water $(9: 1, \mathrm{v} / \mathrm{v})$, as suggested by Grimmer and Bohnke, ${ }^{21}$ and Barranco et al. ${ }^{24}$ The combined extract was concentrated under a flow of nitrogen until it reached approximately $50 \%$ of its initial volume. Then, the resulting solution was diluted with $5 \mathrm{~mL}$ of water and cleaned-up by SPE.

The SPE cartridges (AccuBond ${ }^{\text {II }} 500 \mathrm{mg}, 3 \mathrm{~mL}$ ) were primarily conditioned with $5 \mathrm{~mL}$ of methanol and with $5 \mathrm{~mL}$ of water using a Vacuum Manifold from Supelco® (USA). Subsequently, the sample solution was added and the column was washed with $10 \mathrm{~mL}$ of $N, N$-dimethylformamide-water $(1: 1, \mathrm{v} / \mathrm{v})$, followed by
$10 \mathrm{~mL}$ of water. The cartridges were dried under vacuum for $20 \mathrm{~min}$. Finally, PAHs were eluted with $10 \mathrm{~mL}$ hexane at a flow rate of $2 \mathrm{~mL} \mathrm{~min}^{-1}$ and the elute was evaporated to dryness under a nitrogen stream. The residue was dissolved in $0.5 \mathrm{~mL}$ of acetonitrile and filtered through a $0.45 \mu \mathrm{m}$ filter (PVDF, Millex-HV, Millipore, USA) before the injection into the chromatographic system. Reagent blank controls were analyzed simultaneously in the presence of PAHs with each series of samples. All samples were analyzed in duplicate.

\section{HPLC analysis}

The determination of PAHs was carried out using a Shimadzu HPLC equipment (LC-20A Prominence, Japan) that consisted of a LC-10AT pump, a SIL-20A automatic injector and a RF-10A XL fluorescence detector. A C-18 Vydac 201 TP 54 column $(250 \times 4.6 \mathrm{~mm}, 5 \mu \mathrm{m})$ and an injection volume of $30 \mu \mathrm{L}$ were employed. The temperature of the column was kept constant at $30{ }^{\circ} \mathrm{C}$ to obtain reproducible retention times of PAHs that were detected with the wavelength program described in Table 1 . The mobile phase consisted of acetonitrile (A) and water (B) at a flow rate of $1 \mathrm{~mL} \mathrm{~min}{ }^{-1}$. The optimized elution conditions were: 0-20 min, linear gradient from 70 to $75 \% \mathrm{~A} ; 20-35 \mathrm{~min}$, linear gradient from 75 to $100 \% \mathrm{~A} ; 35-55 \mathrm{~min}, 100 \% \mathrm{~A}$ isocratic; when finally return to the initial conditions in $5 \mathrm{~min}$ and the column is reconditioned for $15 \mathrm{~min}$.

\section{Identification and quantification of PAHs}

The identification of PAHs was performed by comparison of their retention time $\left(t_{R} / \mathrm{min}\right)$ values with those obtained with true standards in the same conditions. Peak identity was also confirmed by spiking the extracts with solutions of the standards co-injection method).

The external standard plot method was used for quantification. From a mixed stock solution prepared

Table 1. Fluorescence detection program for the PAH studied

\begin{tabular}{lccc}
\hline time $/$ min & Excitation wavelength / nm & Emission wavelength / nm & PAH detected \\
\hline 0.01 & 268 & 398 & $\mathrm{~B}[a] \mathrm{A}, \mathrm{Chy}, 5 \mathrm{MeChy}$ \\
16.70 & 312 & 507 & $\mathrm{~B}[j] \mathrm{F}$ \\
18.20 & 290 & 430 & 500 \\
32.40 & 300 & 403 & B $[b] \mathrm{F}, \mathrm{B}[k] \mathrm{F}, \mathrm{B}[a] \mathrm{P}, \mathrm{D}[a l] \mathrm{P}, \mathrm{D}[a h] \mathrm{A}$ \\
34.90 & 297 & 457 & $\mathrm{D}[a e] \mathrm{P}$ \\
45.00 & 304 & $\mathrm{D}[a i] \mathrm{P}, \mathrm{D}[a h] \mathrm{P}$ \\
\hline
\end{tabular}

$\mathrm{B}[a] \mathrm{A}$ : benzo[a]anthracene; Chy: chrysene, $5 \mathrm{MeChy}$ : 5-methylchrysene; $\mathrm{B}[j] \mathrm{F}$ : benzo[j]fluoranthene; $\mathrm{B}[b] \mathrm{F}:$ benzo[ $b]$ fluoranthene; $\mathrm{B}[k] \mathrm{F}$ : benzo $[k]$ fluoranthene; $\mathrm{B}[a] \mathrm{P}$ : benzo $[a]$ pyrene; $\mathrm{D}[a l] \mathrm{P}$ : dibenzo $[a, l]$ pyrene; $\mathrm{D}[a h] \mathrm{A}$ : dibenzo $[a, h]$ anthracene; indeno: indeno $[1,2,3-c d]$ pyrene; $\mathrm{D}[a e] \mathrm{P}$ : dibenzo $[a, e]$ pyrene; $\mathrm{D}[a i] \mathrm{P}$ : dibenzo $[a, i]$ pyrene and $\mathrm{D}[a h] \mathrm{P}$ : dibenzo $[a, h]$ pyrene. 
with 13 PAHs, seven working standard solutions for each calibration curve were obtained by dilution with acetonitrile. The linear regression curves were constructed by plotting the peak area ratios versus each PAH concentrations.

\section{Validation of analytical parameters}

The proposed method was validated for accuracy, precision, linearity, limit of detection (LOD) and limit of quantification (LOQ), according to Institute of Metrology, Standardization and Industrial Quality (Inmetro) guidelines ${ }^{26}$ that comply international requirements. For validation purposes a blank sample of soybean oil was used as reference material. The soybean used to produce this oil was dried naturally before chemical refining in the Institute of Food Technology (ITAL, Campinas-SP, Brazil) in order to avoid any kind of contamination.

Accuracy and repeatability were evaluated by performing recovery tests carried out by spiking sample blanks with PAHs at $0.5,1.0,1.2$ and $5.0 \mu \mathrm{g} \mathrm{kg}^{-1}$. For each concentration level, the spiked samples were analyzed in triplicate during the same day and in three different days. The precision of the chromatographic system was tested by performing intra- and inter-day multiple injections of a PAH standard solution and then checking the RSD of retention times and peak areas. Linearity was established through correlation coefficients $\left(\mathrm{R}^{2}\right)$ of the calibration curves over the range 0.5 to $250 \mathrm{ng} \mathrm{mL}^{-1}$. The LOD and LOQ were determined by seven independent sample blanks fortified with PAHs at level of $0.5 \mu \mathrm{g} \mathrm{kg}^{-1}$ measured once each and the values were calculated as the analyte concentration corresponding to the sample blank values plus a three and five times standard deviation, respectively.

\section{Results and Discussion}

\section{Optimization of the extraction conditions}

In order to establish an efficient solid-phase extraction for the determination of 13 PAHs in soybean oil samples, the different variables involved in the procedure were studied. Initially, a liquid-liquid partition technique with $\mathrm{N}, \mathrm{N}$-dimethylformamide, water and an apolar solvent for the isolation of PAHs was tested for the sample pretreatment. ${ }^{3,21,22}$ Hexane and cyclohexane were both evaluated with different proportions of dimethylformamidewater $(9: 1 ; 5: 1 ; 2: 1$ and $1: 1, \mathrm{v} / \mathrm{v})$. It was found that dimethylformamide-water $(9: 1, \mathrm{v} / \mathrm{v})$ increases the extraction efficiency independent of hexane or cyclohexane use. Even though the solvents have presented the same performance, hexane was adopted in the analysis due to its lower boiling point that permits short time evaporation during the drying step.

Then, different types of silica-based $\mathrm{C}_{18}$ cartridges, applying different amounts of sample $(0.5$ and $1.0 \mathrm{~g})$, were tested to optimize the efficiency of the method (Table S1 from Supplementary Information). The results showed good recoveries using $500 \mathrm{mg}$ of $\mathrm{C}_{18}$ sorbent and $0.5 \mathrm{~g}$ of oil sample. Among $500 \mathrm{mg}$ cartridges, the best performance was obtained with the higher carbon loading, i.e. using the AccuBond $^{\mathrm{II}} 500 \mathrm{mg}, 3 \mathrm{~mL}$.

After choosing the SPE sorbent, other important parameters were also selected and optimized, including type, volume and flow rates of the solvents used during conditioning, rinse and elution steps, likewise the drying time (Table S2).

Good results were obtained by first conditioning with $5 \mathrm{~mL}$ of methanol, followed by $5 \mathrm{~mL}$ of water. To determine the ideal rinsing conditions, a series of washes varying from 10 to $50 \%$ methanol at $10 \%$ increments was applied. It was verified that an increase in the percentage of methanol negatively influenced on the extraction efficiency. In contrast the use of dimethylformamidewater $(1: 1, \mathrm{v} / \mathrm{v})$, as suggested by Barranco et al.,$^{24}$ followed by pure water improved the method recovery and reproducibility.

Drying of the SPE cartridge before PAHs elution is another parameter that should be taken into account during the procedure. This step contributed to obtain good results of recovery and repeatability. ${ }^{2} \mathrm{~A}$ time of $20 \mathrm{~min}$ was considered sufficient to reach a dried cartridge before PAHs elution.

The appropriated hexane volume to elute quantitatively all 13 PAHs was $10 \mathrm{~mL}$, at a flow rate of $2 \mathrm{~mL} \mathrm{~min}^{-1}$. It was observed that better recoveries were achieved as slow as the solvent flowed through the SPE cartridge.

\section{HPLC method development and optimization}

In order to obtain a satisfactory separation of the PAHs considered in this study, initially two different reversedphase chromatographic columns were used: a C18 Vydac 201 TP 54 column $(250 \times 4.6 \mathrm{~mm}, 5 \mu \mathrm{m}$ particle size $)$ and a C18 Supelcosil ${ }^{\mathrm{TM}}$ LC PAH $(250 \times 4.6 \mathrm{~mm}, 5 \mu \mathrm{m}$ particle size). The performance of these columns was firstly tested on a standard mixture of the 13 PAHs: benzo $[a]$ anthracene, benzo $[b]$ fluoranthene, benzo[j]fluoranthene, benzo[k]fluoranthene, benzo[ $a]$ pyrene, dibenzo $[a, h]$ anthracene, dibenzo $[a, e]$ pyrene dibenzo $[a, h]$ pyrene, dibenzo $[a, i]$ pyrene, dibenzo $[a, l]$ pyrene, indeno $[1,2,3-c d]$ pyrene, chrysene and 5-methylchrysene, at a concentration 
of $1 \mathrm{ng} \mathrm{mL} \mathrm{m}^{-1}$. Although both columns presented good chromatographic efficiency and reproducibility, the resolution achieved with the $\mathrm{Vydac} \mathrm{C}_{18}$ column was better than that obtained using the other one, especially for the pair of compounds dibenzo $[a, l]$ pyrene and dibenz $[a, h]$ anthracene.

Then, chromatographic conditions, such as mobile phase gradient, flow rate, column temperature and injection volume, were evaluated in order to obtain the best resolution in the shortest analysis time. Gradients of different proportions of acetonitrile and water were tested. The conditions presented above (see HPLC analysis) led to well resolved peaks in a reasonable running time. The influence of temperature on the PAH resolution was investigated by setting the oven at 27,30 and $32^{\circ} \mathrm{C}$ and the best separation was achieved at $30{ }^{\circ} \mathrm{C}$. A flow rate of $1.0 \mathrm{~mL} \mathrm{~min}^{-1}$ was appropriated to obtain good separation, maintaining a good chromatographic quality and analysis time.

The best excitation and emission wavelengths were selected after recording the excitation and emission fluorescence spectra of each PAH. Five different excitation/ emission wavelength combinations were applied and the compounds are grouped to permit both detection and separation during the chromatographic run (Table 1).

Figure 2(a) shows a typical chromatogram of a standard mixture of PAHs under the best chromatographic conditions (elution gradient and detection program) and Figure 2(b) shows a typical chromatogram of a sample extract obtained under the same conditions.
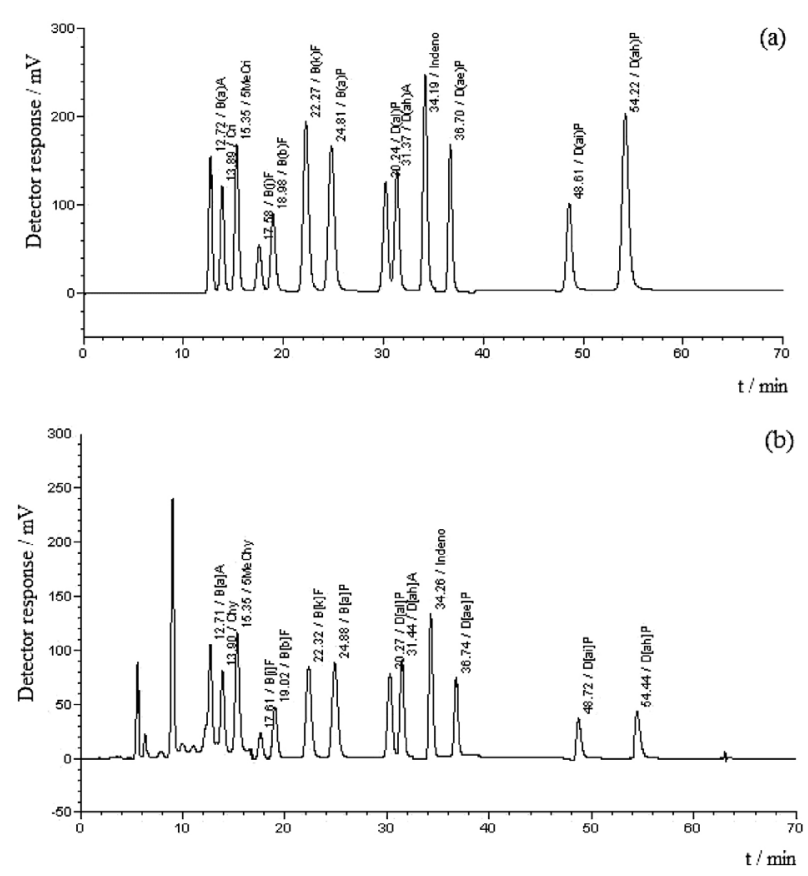

Figure 2. HPLC chromatogram of (a) PAH standard solution and (b) commercial soybean oil sample.

\section{Method validation}

The described method was developed to provide a quality control determination of PAHs in edible oils. Validation was performed according to the Inmetro ${ }^{26}$ parameters.

The accuracy of the analytical procedure was evaluated through recovery experiments after spiking a blank sample of soybean oil with three different concentrations of PAHs $\left(0.5,1.0\right.$ and $\left.5.0 \mu \mathrm{g} \mathrm{kg}^{-1}\right)$. Independent triplicates of the fortified samples were analyzed and the obtained values were reported as percent recoveries. Mean recoveries between 71 and $115 \%$ were obtained for almost all studied compounds, except for dibenzo[a,i]pyrene, which showed recovery values between 61 and 66\% (Table S3). Although it is desirable to obtain recoveries as close to $100 \%$ as possible, the results are in agreement with the criteria for methods of analysis for benzo(a)pyrene provided by Regulation EC N. 333. ${ }^{27}$ Thus, the method accuracy was considered adequate for all PAHs analyzed.

The precision (repeatability) studies of the extraction procedure and SPE purification were determined by repeating the whole procedure in triplicate on three different days. The blank control samples were fortified with $1.2 \mu \mathrm{g} \mathrm{kg}^{-1}$ PAHs. Inter- and intra-day repeatabilities, expressed as the percentage of relative standard deviation (\% RSD), are presented on Table S4. The values indicate a satisfactory precision of the method for determinations at $\mu \mathrm{g} \mathrm{kg}^{-1}$ levels. ${ }^{28,29} \mathrm{In}$ addition, the precision of the chromatographic system was carried out by injecting the same oil sample extract, fortified with a working standard PAHs solution $\left(1.2 \mu \mathrm{g} \mathrm{kg}^{-1}\right)$ five times $(\mathrm{n}=5)$, during three consecutive days $(n=3)$ and then checking the RSD of retention times and peak areas. The low values found within and between days for both parameters show the high precision of the chromatographic system, once the RSD of the detector response was lower than $1.5 \%$ (including intraand inter-day repeatability) and the RSD of the retention times was lower than $0.09 \%$ for each PAH.

Linearity was evaluated by the determination coefficients $\left(\mathrm{R}^{2}\right)$ of the analytical curves constructed with seven standard solution different concentrations. The parameters obtained for the calibration equation of each PAH (slope $=\mathrm{a}$, intercept $=\mathrm{b}$ and $\mathrm{R}^{2}$ ), likewise the linear range are shown in Table S5. Good linearity was observed between peak areas and concentrations over the studied range.

LODs and LOQs of individual PAHs were determined using spiked matrices. For this purpose, 7 independent soybean oil samples (blank) spiked with PAHs at a level of $0.5 \mu \mathrm{g} \mathrm{kg}^{-1}$ were analyzed. The LOD and the LOQ were calculated as the analyte concentration corresponding to, 
respectively, mean fortified sample blank value $+3 \mathrm{~s}$ and mean fortified sample blank value $+5 \mathrm{~s}$, where $s$ is the standard deviation of the fortified blank mean. In this case the mean and the standard deviation are dependent on the matrix of the sample blank. The limits of detection and quantification determined in this study for the target compounds ranged from 0.02 to $0.76 \mu \mathrm{g} \mathrm{kg}^{-1}$ and 0.03 to $0.96 \mu \mathrm{g} \mathrm{kg}^{-1}$, respectively (Table S6).

\section{Analysis of PAHs in soybean oils}

The optimized method was applied in commercial samples of soybean oils most frequently consumed in the metropolitan area of Campinas-SP (Brazil). Table 2 presents the means and ranges of PAHs concentrations determined in oils. As can be observed, there is no pattern for PAH contamination in this kind of product and a relatively wide variation within batches, brands and periods of time were found. The compounds were detected in all samples analyzed but brand B was the only one that presented all 13 PAHs evaluated. Dibenzo[ah]pyrene was the lowest representative PAH, once it was found in only one sample analyzed. Mean and maximum levels of individual PAHs ranged from < LOQ to $6.20 \mu \mathrm{g} \mathrm{kg}^{-1}$ and 0.22 to $12.36 \mu \mathrm{g} \mathrm{kg}^{-1}$, respectively. In both years, brand B presented the highest mean PAH contamination, summed $22.72 \mu \mathrm{g} \mathrm{kg}^{-1}$ in 2007 and $35.97 \mu \mathrm{g} \mathrm{kg}^{-1}$ in 2008 . Otherwise, brand C showed in 2007 the lowest PAHs levels $\left(6.22 \mu \mathrm{g} \mathrm{kg}^{-1}\right)$, while in 2008 the quantities determined were about three times higher $\left(18.32 \mu \mathrm{g} \mathrm{kg}^{-1}\right)$.

Various sources can be responsible for the presence of these contaminants in vegetable oils, but the large variability in contamination is probably due to the oil processing. The drying step, where combustion gases are in direct contact with the oil seeds, has been shown to be responsible for the introduction of most PAHs in the crude edible oil..$^{14,19,20}$ While refining reduces the levels of a number of lower molecular weight PAHs, no corresponding effect has been observed for the higher molecular weight compounds. Although the use of active carbon in the process is highly efficient to reduce the PAHs in oils, especially the heavy fraction (5 and more aromatic rings), this adsorbent has not yet been used by the oil refineries in Brazil, resulting in the presence of these compounds in commercial refined vegetable oils.

Considering the benzo $[a]$ pyrene for comparison purposes, the mean levels determined (0.27-1.94 $\left.\mu \mathrm{g} \mathrm{kg}^{-1}\right)$ in most brands evaluated were lower than the limit established for this PAH in oils $\left(2.0 \mu \mathrm{g} \mathrm{kg}^{-1}\right)$ by the Commission Regulation (EC). ${ }^{13}$ Therefore, the benzo[a] pyrene concentration found in brand B, collected in 2008, was about four times higher $\left(3.96 \mu \mathrm{g} \mathrm{kg}^{-1}\right)$ than the level

Table 2. Mean PAH levels in soybean oil

\begin{tabular}{|c|c|c|c|c|c|c|}
\hline \multicolumn{7}{|c|}{ Oil samples $(\mathrm{A}, \mathrm{B}, \mathrm{C})$ : mean concentration of PAHs / $\mu \mathrm{g} \mathrm{kg}^{-1}(\text { range })^{\mathrm{a}}$} \\
\hline \multirow[t]{2}{*}{ PAH } & \multicolumn{3}{|c|}{2007} & \multicolumn{3}{|c|}{2008} \\
\hline & A & $\mathrm{B}$ & $\mathrm{C}$ & A & $\mathrm{B}$ & $\mathrm{C}$ \\
\hline $\mathrm{B}[a] \mathrm{A}$ & $4.07(1.11-7.34)$ & $3.12(2.41-4.01)$ & $0.92(0.24-1.84)$ & $3.86(0.71-9.31)$ & $6.20(3.31-10.58)$ & $3.11(1.80-4.87)$ \\
\hline Chy & $4.66(1.77-8.21)$ & $5.93(3.24-7.85)$ & $2.24(1.41-2.95)$ & $4.81(1.36-10.99)$ & $5.87(3.02-10.60)$ & $3.22(2.34-4.37)$ \\
\hline 5MeChy & $1.54(0.54-4.07)$ & $2.03(1.51-2.56)$ & $0.78(0.66-0.90)$ & $0.85(0.42-1.48)$ & $0.77(0.66-0.98)$ & $2.19(0.45-5.45)$ \\
\hline $\mathrm{B}[j] \mathrm{F}$ & n.d. $-<0.65$ & $1.65(0.72-2.33)$ & n.d. $-<0.65$ & $1.50(<0.65-4.49)$ & $1.75(<0.65-3.49)$ & n.d. $-<0.65$ \\
\hline $\mathrm{B}[b] \mathrm{F}$ & $1.50(0.41-3.89)$ & $1.57(0.31-2.87)$ & $0.62(0.36-0.87)$ & $3.42(0.67-8.45)$ & $3.62(1.67-6.00)$ & $1.30(1.02-1.50)$ \\
\hline $\mathrm{B}[k] \mathrm{F}$ & $0.68(0.50-1.94)$ & $0.92(0.45-1.50)$ & $0.26(0.25-0.28)$ & $1.08(0.19-2.73)$ & $1.37(0.42-2.60)$ & $0.59(0.50-0.64)$ \\
\hline $\mathrm{B}[a] \mathrm{P}$ & $1.04(0.25-2.02)$ & $1.10(0.39-1.69)$ & $0.27(0.25-0.30)$ & $1.94(0.18-5.46)$ & $3.96(0.57-7.00)$ & $0.81(0.48-1.02)$ \\
\hline $\mathrm{D}[a l] \mathrm{P}$ & n.d. $-<0.20$ & $0.26(<0.20-0.78)$ & $0.31(<0.20-0.55)$ & $0.20(<0.20-0.32)$ & $0.20(<0.20-0.22)$ & n.d. $-<0.20$ \\
\hline $\mathrm{D}[a h] \mathrm{A}$ & $2.11(0.79-3.46)$ & $3.03(0.59-4.50)$ & $0.61(0.20-0.85)$ & $1.31(0.99-2.41)$ & $4.13(0.63-8.50)$ & $0.95(0.62-1.19)$ \\
\hline Indeno & n.d. $-<0.90$ & $2.28(0.85-3.84)$ & n.d. $-<0.90$ & $2.57(0.83-5.24)$ & $4.87(2.50-6.40)$ & $4.85(0.55-12.36)$ \\
\hline $\mathrm{D}[a e] \mathrm{P}$ & $0.52(0.61-1.63)$ & $0.52(0.36-0.88)$ & $0.21(0.12-0.39)$ & $0.68(0.37-1.26)$ & $0.79(0.54-1.00)$ & $0.90(0.63-1.24)$ \\
\hline $\mathrm{D}[a i] \mathrm{P}$ & $0.51(0.41-2.21)$ & $0.31(<0.25-0.73)$ & n.d. $-<0.25$ & $1.46(0.38-2.57)$ & $1.50(0.28-3.75)$ & $0.40(<0.25-0.70)$ \\
\hline $\mathrm{D}[a h] \mathrm{P}$ & n.d. $-<0.96$ & n.d. $-<0.96$ & n.d. $-<0.96$ & n.d. $-<0.96$ & $0.96(<0.96-1.50)$ & n.d. $-<0.96$ \\
\hline$\Sigma$ PAHs & $16.63(6.39-37.48)$ & $22.72(11.28-34.50)$ & $6.22(3.69-11.69)$ & $23.68(6.95-55.67)$ & $35.89(15.41-62.62)$ & $18.32(8.64-35.15)$ \\
\hline
\end{tabular}

$\mathrm{B}[a] \mathrm{A}:$ benzo $[a]$ anthracene; Chy: chrysene; $5 \mathrm{MeChy}$ : 5-methylchrysene; $\mathrm{B}[j] \mathrm{F}$ : benzo[j]fluoranthene; $\mathrm{B}[b] \mathrm{F}:$ benzo $[b]$ fluoranthene; $\mathrm{B}[k] \mathrm{F}:$ benzo $[k]$ fluoranthene; $\mathrm{B}[a] \mathrm{P}$ : benzo $[a]$ pyrene; $\mathrm{D}[a l] \mathrm{P}$ : dibenzo $[a, l]$ pyrene; $\mathrm{D}[a h] \mathrm{A}$ : dibenzo $[a, h]$ anthracene; indeno: indeno[ $1,2,3-c d]$ pyrene; $\mathrm{D}[a e] \mathrm{P}:$ dibenzo $[a, e]$ pyrene; D[ai]P: dibenzo[a,i]pyrene; D $[a h] \mathrm{P}$ : dibenzo[a,h]pyrene; ${ }^{a}$ mean of 8 determinations (4 batches in duplicate)/brand/year; n.d.: not detected; the range of $\Sigma$ PAHs was calculated taking values $<$ LOQ to be equal to $L O Q$. 
found previously (2007) for the same brand $\left(1.10 \mu \mathrm{g} \mathrm{kg}^{-1}\right)$ and exceeds the maximum level permitted in oils. ${ }^{13}$

Earlier studies conducted by Pupin and Toledo ${ }^{14}$ also showed that commercial Brazilian soybean oils contained benzo $[a]$ pyrene at relatively higher concentration $\left(2.30 \mu \mathrm{g} \mathrm{kg}^{-1}\right)$ as compared to the mean range found in the present study for most brands investigated.

Since there was a great variability in the PAH oil contamination profile and considering that the summed PAHs values exceeding $2.00 \mu \mathrm{g} \mathrm{kg}^{-1}$ were found, B[a]P is not a suitable indicator for the occurrence of other PAHs in this food group.

Based on the results, further investigation should be extend to other brands of soybean oil available in the Brazilian market and a monitoring program should be developed in order to avoid any risk to the consumers. The proposed method is appropriate for the quality control of soybean oils.

\section{Conclusions}

This work describes a SPE-LC-FLD method for the determination of PAHs in vegetable oils. The method provided detection and quantification limits between $0.02-0.76 \mu \mathrm{g} \mathrm{kg}^{-1}$ and $0.03-0.96 \mu \mathrm{g} \mathrm{kg}^{-1}$, respectively. Recoveries over $70 \%$ were obtained and the calibration curves were linear at the tested ranges $\left(R^{2}>0.999\right)$. Variable levels of contamination were found within different brands and within different batches of the same brand at concentration levels below and above the maximum limits established in the EUA legislation.

In summary, optimization of the extraction procedure and establishment of the optimal chromatographic separation conditions resulted in a reliable method for the 13 PAHs simultaneous determination in soybean oils and can be applied to evaluate the contamination of different types of edible oils. The method proved to be efficient for a precise and accurate quantification of the compounds being an option for other complex matrices and is applicable to routine analysis.

\section{Supplementary Information}

Tables S1-S6 with comparison of the evaluated solid phase extraction (SPE) cartridges, parameters tested during the optimization of the extraction conditions, likewise the parameters of validation (recovery, inter- and intraday precision, LOD, LOQ and the statistical parameters of the calibration lines) are available free of charge at http://jbcs.sbq.org.br as PDF file.

\section{Acknowledgements}

Financial support from Fundação de Amparo à Pesquisa do Estado de São Paulo (FAPESP, proc. 05/59974-8) and scholarship from Conselho Nacional de Desenvolvimento Científico e Tecnológico (CNPq) are gratefully acknowledged.

\section{References}

1. World Health Organization (WHO); Summary and Conclusions of the Sixty-Fourth Meeting of the Joint FAO/WHO Expert Committee on Food Additives, World Health Organization: Rome, 2005.

2. Moret, S.; Conte, L. S.; J. Chromatogr., A 2000, 882, 245.

3. Camargo, M. C. R.; Toledo M. C. F.; Food Control 2003, 14, 49.

4. Camargo, M. C. R.; Tfouni, S. A. V.; Vitorino, S. H. P.; Menegário, T. F.; Toledo M. C. F.; Ciênc. Tecnol. Aliment. 2006, 26, 230.

5. Barranco,A.; Salces, R. M.A.; Crespo, I.; Berrueta, L.A.; Gallo, B.; Vicente, F.; Sarobe, M.; J. Food Prot. 2004, 67, 2786.

6. Bishnoi, N. R.; Mehta, U.; Sain, U.; Pandit, G. G.; Environ. Monit. Assess. 2005, 107, 399.

7. Fálcon, M. S. G.; Grande, B. C.; Gándara, J. G.; Food Chem. 2005, 90, 643.

8. Badolato, E. S. G.; Martins, M. S.; Pimentel, S. A.; Alaburda, J.; Kumagai, E. E.; Baptista, G. G.; Rosenthal, A.; J. Braz. Chem. Soc. 2006, 17, 989.

9. Vichi, S.; Pizzale, L.; Conte, S. L.; Buxaderas, S.; Tamames, E. L.; Food Control 2007, 18, 1204.

10. Salgueiro, L. R.; Falcón, S. G.; Carballo, E. M.; Gándara, J. S.; Food Chem. 2008, 108, 607.

11. Tfouni, S. A. V.; Souza, N. G.; Neto, M. B.; Loredo, I. S. D.; Leme, F. M.; Furlani, R. P. Z.; Food Chem. 2009, 116, 291.

12. Orecchio, S.; Ciotti, V. P.; Culotta, L.; Food Chem. Toxicol. 2009, 47, 819 .

13. The Commission of the European Communities; Commission Regulation (EC) No 208/2005, Official Journal of the European Union, 2005, L34/3.

14. Pupin, A. M.; Toledo M. C. F.; Food Addit. Contam. 1996, 13, 639.

15. Noll, I. B.; Toledo, M. C. F.; Rev. Bras. Toxicol. 1997, 10, 19.

16. Camargo, M. C. R.; Toledo M. C. F.; Braz. J. Food Technol. 2002, 5, 19.

17. Camargo, M. C. R.; Toledo, M. C. F.; Ciênc. Tecnol. Aliment. 2002, 22, 49.

18. Tfouni, S. A. V.; Machado, R. M. D.; Camargo, M. C. R.; Vitorino, S. H. V.; Vicente, E.; Toledo, M. C. F.; Food Chem. 2007, 101, 334.

19. Teixeira, V. H.; Casal, S.; Oliveira, M. B. P. P.; Food Chem. 2007, 104, 106. 
20. Camargo, M. S. F. O.; Toledo, M. C. F.; Braz. J. Food Technol. 1998, $1,97$.

21. Grimmer, G.; Bohnke, H.; J. AOAC 1975, 58, 724.

22. Speer, K.; Steeg, E.; Hortsmann, P.; Kuhn T.; Montag, A.; J. High Resolut. Chromatogr. 1990, 13, 104.

23. Zougagh, M.; Redigolo, H.; Rios A.; Valcárcel M.; Anal. Chim. Acta 2004, 525, 265.

24. Barranco, A.; Salces R. M. A.; Berrueta, L. A., Gallo, B.; Vicente, F.; Sarobe, M.; J. Sep. Sci. 2003, 26, 1554.

25. Marcé, R. M.; Borrull, F.; J. Chromatogr., A 2000, 885, 273.

26. INMETRO, Instituto Nacional de Metrologia; Normalização e Qualidade Industrial, Orientações sobre Validação de
Métodos de Ensaios Químicos, Documento DOQ-CGCRE-008, Revisão 2, Brasil, 2007.

27. The Commission of the European Communities; Commission Regulation (EC) No 333/2007, Official Journal of the European Union, 2007, L88/29.

28. Horwitz, W.; Kamps, L. R.; Boyer, K. W.; J. AOAC 1980, 63, 1344.

29. Jenke, D.; J. Liq. Chromatogr. Relat. Technol. 1996, 19, 737.

Submitted: August 23, 2010

Published online: March 24, 2011

FAPESP has sponsored the publication of this article. 


\title{
HPLC-FLD Simultaneous Determination of 13 Polycyclic Aromatic Hydrocarbons: Validation of an Analytical Procedure for Soybean Oils
}

\author{
Mônica C. R. Camargo, ${ }^{*, a}$ Paula R. Antoniolli ${ }^{b}$ and Eduardo Vicente ${ }^{a}$
}

${ }^{a}$ Centro de Ciência e Qualidade de Alimentos, Instituto de Tecnologia de Alimentos,

Av. Brasil, 2880, 13070-178 Campinas-SP, Brazil

${ }^{b}$ Instituto de Química, Universidade Estadual de Campinas, 13083-970 Campinas-SP, Brazil

Table S1. Comparison of the evaluated solid phase extraction (SPE) cartridges

\begin{tabular}{|c|c|c|c|c|c|}
\hline Sorbent & Producer & $\begin{array}{l}\text { Sorbent mass / mg, } \\
\text { column volume / mL }\end{array}$ & Porous / $\AA$ & Endcapped & Carbon loading / \% \\
\hline BondElut & Varian & 500,3 & 60 & yes & 17.0 \\
\hline AccuBond ${ }^{\mathrm{II}}$ ODS C18 & Agilent & 500,3 & 60 & yes & 19.0 \\
\hline AccuBond ${ }^{\mathrm{II}}$ ODS C18 & Agilent & 1000,6 & 60 & yes & 18.0 \\
\hline Strata C18-E & Phenomenex & 500,3 & 64 & yes & 17.1 \\
\hline Chromabond ec C18 & Macherey-Nagel & 500,3 & 60 & yes & 14.0 \\
\hline
\end{tabular}

Table S2. Parameters tested during the optimization of the extraction conditions

\begin{tabular}{lll}
\hline Parameters & Variable & Best condition \\
\hline Conditioning solvent & methanol, dimethylformamide, water & dimethylformamide \\
Rinse solvent & methanol, methanol-water, water, dimethylformamide-water & dimethylformamide-water \\
Elution solvent & hexane, cyclohexane & hexane \\
Flow rate & 6,4 and $2 \mathrm{~mL} \mathrm{~min}^{-1}$ & $2 \mathrm{~mL} \mathrm{~min}^{-1}$ \\
Cartridge drying step & 10,15 and $20 \mathrm{~min}^{-1}$ & $20 \mathrm{~min}$ \\
Eluent volume & 4,8 and $10 \mathrm{~mL}$ & $10 \mathrm{~mL}$ \\
\hline
\end{tabular}

*e-mail: monicarojo@uol.com.br 
Table S3. Recoveries (\%) of the studied PAHs (mean value \pm standard deviation) from soybean oils

\begin{tabular}{|c|c|c|c|}
\hline \multirow[t]{2}{*}{ PAH } & \multicolumn{3}{|c|}{ Recovery $/ \%($ mean $\pm \mathrm{RSD}, \mathrm{n}=3)$} \\
\hline & Spiked level: $0.5 \mu \mathrm{g} \mathrm{kg}^{-1}$ & Spiked level: $1.0 \mu \mathrm{g} \mathrm{kg}^{-1}$ & Spiked level: $5.0 \mu \mathrm{g} \mathrm{kg}^{-1}$ \\
\hline $\mathrm{B}[a] \mathrm{A}$ & $91 \pm 3.1$ & $94 \pm 5.4$ & $93 \pm 3.8$ \\
\hline Chy & $82 \pm 6.3$ & $88 \pm 11.2$ & $85 \pm 2.8$ \\
\hline 5MeChy & $115 \pm 8.4$ & $109 \pm 1.5$ & $107 \pm 2.1$ \\
\hline $\mathrm{B}[j] \mathrm{F}$ & $81 \pm 2.5$ & $85 \pm 2.7$ & $88 \pm 2.9$ \\
\hline $\mathrm{B}[b] \mathrm{F}$ & $85 \pm 4.7$ & $82 \pm 1.2$ & $84 \pm 3.7$ \\
\hline $\mathrm{B}[k] \mathrm{F}$ & $81 \pm 3.6$ & $84 \pm 1.6$ & $81 \pm 2.2$ \\
\hline $\mathrm{B}[a] \mathrm{P}$ & $102 \pm 3.8$ & $102 \pm 2.5$ & $98 \pm 6.5$ \\
\hline $\mathrm{D}[a l] \mathrm{P}$ & $71 \pm 11.9$ & $88 \pm 4.7$ & $87 \pm 3.9$ \\
\hline $\mathrm{D}[a h] \mathrm{A}$ & $106 \pm 1.9$ & $97 \pm 3.2$ & $95 \pm 4.1$ \\
\hline Indeno & $73 \pm 8.4$ & $77 \pm 5.9$ & $71 \pm 3.3$ \\
\hline $\mathrm{D}[a e] \mathrm{P}$ & $94 \pm 3.1$ & $91 \pm 6.7$ & $98 \pm 1.0$ \\
\hline $\mathrm{D}[a i] \mathrm{P}$ & $61 \pm 4.7$ & $66 \pm 1.2$ & $63 \pm 4.2$ \\
\hline $\mathrm{D}[a h] \mathrm{P}$ & $92 \pm 2.0$ & $96 \pm 6.3$ & $94 \pm 1.1$ \\
\hline
\end{tabular}

$\mathrm{B}[a] \mathrm{A}$ : benzo $[a]$ anthracene; Chy: chrysene; $5 \mathrm{MeChy:} \mathrm{5-methylchrysene;} \mathrm{B}[j] \mathrm{F}$ : benzo[j]fluoranthene; $\mathrm{B}[b] \mathrm{F}$ : benzo $[b]$ fluoranthene; $\mathrm{B}[k] \mathrm{F}:$ benzo $[k]$ fluoranthene; $\mathrm{B}[a] \mathrm{P}$ : benzo $[a]$ pyrene; $\mathrm{D}[a l] \mathrm{P}$ : dibenzo $[a, l]$ pyrene; $\mathrm{D}[a h] \mathrm{A}$ : dibenzo $[a, h]$ anthracene; indeno: indeno[ $[1,2,3-c d]$ pyrene; $\mathrm{D}[a e] \mathrm{P}:$ dibenzo $[a, e]$ pyrene; D $[a i] \mathrm{P}$ : dibenzo $[a, i]$ pyrene; D $[a h] \mathrm{P}$ : dibenzo $[a, h]$ pyrene; RSD: relative standard deviation.

Table S4. Intra- and inter-day precision data for the extraction of PAHs from soybean oils

\begin{tabular}{|c|c|c|c|c|c|c|c|c|}
\hline \multirow[t]{3}{*}{$\mathrm{PAH}$} & \multicolumn{6}{|c|}{ Intra-day precision $(\mathrm{n}=3$, mean $)$} & \multirow{2}{*}{\multicolumn{2}{|c|}{$\begin{array}{c}\text { Inter-day precision }(\mathrm{n}=9, \text { mean }) \\
\text { Days } 1,2 \text { and } 3\end{array}$}} \\
\hline & \multicolumn{2}{|c|}{ Day 1} & \multicolumn{2}{|c|}{ Day 2} & \multicolumn{2}{|c|}{ Day 3} & & \\
\hline & Content $/ \mu \mathrm{g} \mathrm{kg}^{-1}$ & $\mathrm{RSD} / \%$ & Content $/ \mu \mathrm{g} \mathrm{kg}^{-1}$ & $\mathrm{RSD} / \%$ & Content $/ \mu \mathrm{g} \mathrm{kg}^{-1}$ & $\mathrm{RSD} / \%$ & Content $/ \mu \mathrm{g} \mathrm{kg}^{-1}$ & $\mathrm{RSD} / \%$ \\
\hline $\mathrm{B}[a] \mathrm{A}$ & 1.23 & 2.15 & 1.17 & 1.30 & 1.22 & 2.87 & 1.21 & 2.66 \\
\hline Chy & 1.11 & 6.76 & 1.12 & 6.82 & 1.06 & 4.32 & 1.10 & 2.92 \\
\hline 5MeChy & 1.39 & 4.31 & 1.34 & 4.16 & 1.42 & 1.40 & 1.38 & 2.93 \\
\hline $\mathrm{B}[j] \mathrm{F}$ & 1.12 & 5.45 & 1.23 & 1.62 & 1.10 & 2.41 & 1.15 & 6.09 \\
\hline $\mathrm{B}[b] \mathrm{F}$ & 1.02 & 5.39 & 0.96 & 3.13 & 1.04 & 2.54 & 1.01 & 4.12 \\
\hline $\mathrm{B}[k] \mathrm{F}$ & 1.04 & 1.47 & 1.11 & 2.90 & 1.01 & 1.98 & 1.05 & 4.88 \\
\hline $\mathrm{B}[a] \mathrm{P}$ & 1.22 & 1.42 & 1.22 & 2.06 & 1.23 & 1.24 & 1.22 & 0.47 \\
\hline $\mathrm{D}[a l] \mathrm{P}$ & 1.08 & 8.83 & 1.06 & 4.99 & 1.06 & 3.81 & 1.07 & 1.08 \\
\hline $\mathrm{D}[a h] \mathrm{A}$ & 1.18 & 2.13 & 1.15 & 3.98 & 1.13 & 1.35 & 1.15 & 2.19 \\
\hline Indeno & 0.95 & 3.79 & 1.02 & 2.99 & 0.94 & 3.73 & 0.97 & 4.49 \\
\hline $\mathrm{D}[a e] \mathrm{P}$ & 1.08 & 5.78 & 1.15 & 5.24 & 1.09 & 4.61 & 1.11 & 3.41 \\
\hline $\mathrm{D}[a i] \mathrm{P}$ & 0.88 & 3.68 & 0.90 & 5.19 & 0.98 & 7.52 & 0.92 & 5.75 \\
\hline $\mathrm{D}[a h] \mathrm{P}$ & 1.19 & 3.97 & 1.22 & 2.06 & 1.16 & 4.42 & 1.19 & 2.52 \\
\hline
\end{tabular}

$\mathrm{B}[a] \mathrm{A}$ : benzo $[a]$ anthracene; Chy: chrysene; $5 \mathrm{MeChy:} \mathrm{5-methylchrysene;} \mathrm{B}[j] \mathrm{F}$ : benzo[j]fluoranthene; $\mathrm{B}[b] \mathrm{F}$ : benzo $[b]$ fluoranthene; $\mathrm{B}[k] \mathrm{F}$ : benzo $[k]$ fluoranthene; $\mathrm{B}[a] \mathrm{P}$ : benzo $[a]$ pyrene; $\mathrm{D}[a l] \mathrm{P}$ : dibenzo $[a, l]$ pyrene; $\mathrm{D}[a h] \mathrm{A}$ : dibenzo $[a, h]$ anthracene; indeno: indeno $[1,2,3-c d]$ pyrene; $\mathrm{D}[a e] \mathrm{P}: \operatorname{dibenzo}[a, e]$ pyrene; D $[a i] \mathrm{P}$ : dibenzo $[a, i]$ pyrene; $\mathrm{D}[a h] \mathrm{P}$ : dibenzo[ $a, h]$ pyrene; RSD: relative standard deviation. 
Table S5. Statistical parameters of the calibration equations of individual PAHs

\begin{tabular}{|c|c|c|c|c|}
\hline PAH & Concentration range / $\mu \mathrm{g} \mathrm{mL}^{-1}$ & Slope (a ) $\times 10^{8 \mathrm{a}}$ & Intercept $(b) \times 10^{4 a}$ & $\mathrm{R}^{2 \mathrm{a}}$ \\
\hline $\mathrm{B}[a] \mathrm{A}$ & $0.0005-0.05$ & 2.83 & -1.06 & 0.9994 \\
\hline Chy & $0.0005-0.05$ & 2.47 & -5.21 & 0.9994 \\
\hline 5MeChy & $0.0005-0.05$ & 3.66 & -2.54 & 0.9998 \\
\hline $\mathrm{B}[j] \mathrm{F}$ & $0.001-0.25$ & 0.06 & -0.04 & 0.9999 \\
\hline $\mathrm{B}[b] \mathrm{F}$ & $0.0005-0.05$ & 1.18 & -3.41 & 0.9993 \\
\hline $\mathrm{B}[k] \mathrm{F}$ & $0.0005-0.05$ & 5.85 & -4.80 & 0.9990 \\
\hline $\mathrm{B}[a] \mathrm{P}$ & 0.0005-0.05 & 5.24 & 8.28 & 0.9998 \\
\hline $\mathrm{D}[a l] \mathrm{P}$ & $0.0005-0.05$ & 1.59 & -1.56 & 0.9993 \\
\hline $\mathrm{D}[a h] \mathrm{A}$ & 0.0005-0.05 & 1.68 & -8.29 & 0.9984 \\
\hline Indeno & $0.001-0.25$ & 0.28 & -3.28 & 0.9997 \\
\hline $\mathrm{D}[a e] \mathrm{P}$ & $0.0005-0.05$ & 3.60 & -9.43 & 0.9999 \\
\hline $\mathrm{D}[a i] \mathrm{P}$ & 0.0005-0.05 & 1.23 & -0.52 & 0.9967 \\
\hline $\mathrm{D}[a h] \mathrm{P}$ & $0.0005-0.05$ & 1.20 & -1.31 & 0.9993 \\
\hline
\end{tabular}

$\mathrm{B}[a] \mathrm{A}$ : benzo $[a]$ anthracene; Chy: chrysene; $5 \mathrm{MeChy:} 5$-methylchrysene; $\mathrm{B}[j] \mathrm{F}$ : benzo[j]fluoranthene; $\mathrm{B}[b] \mathrm{F}$ : benzo $[b]$ fluoranthene; $\mathrm{B}[k] \mathrm{F}:$ benzo $[k]$ fluoranthene; $\mathrm{B}[a] \mathrm{P}$ : benzo $[a]$ pyrene; $\mathrm{D}[a l] \mathrm{P}$ : dibenzo $[a, l]$ pyrene; $\mathrm{D}[a h] \mathrm{A}$ : dibenzo $[a, h]$ anthracene; Indeno: indeno $[1,2,3-c d]$ pyrene; $\mathrm{D}[a e] \mathrm{P}:$ dibenzo $[a, e]$ pyrene; $\mathrm{D}[a i] \mathrm{P}$ : dibenzo $[a, i]$ pyrene; $\mathrm{D}[a h] \mathrm{P}$ : dibenzo $[a, h]$ pyrene; ${ }^{\mathrm{a}} \mathrm{y}=\mathrm{ax}+\mathrm{b}$ : regression equation for each curve, where $\mathrm{y}=$ peak area, $\mathrm{x}=$ analyte concentration $\left(\mu \mathrm{g} \mathrm{mL}^{-1}\right) ; \mathrm{a}=$ slope; $\mathrm{b}=$ intercept and $\mathrm{R}^{2}=$ coefficient of determination.

Table S6. Limits of detection (LOD) and quantification (LOQ) of the studied PAHs

\begin{tabular}{lcc}
\hline PAH & LOD & LOQ \\
\hline $\mathrm{B}[a] \mathrm{A}$ & 0.03 & 0.05 \\
Chy & 0.02 & 0.03 \\
$5 \mathrm{MeChy}$ & 0.16 & 0.27 \\
$\mathrm{~B}[j] \mathrm{F}$ & 0.39 & 0.65 \\
$\mathrm{~B}[b] \mathrm{F}$ & 0.20 & 0.35 \\
$\mathrm{~B}[k] \mathrm{F}$ & 0.16 & 0.25 \\
$\mathrm{~B}[a] \mathrm{P}$ & 0.16 & 0.25 \\
$\mathrm{D}[a]] \mathrm{P}$ & 0.12 & 0.20 \\
$\mathrm{D}[a h] \mathrm{A}$ & 0.15 & 0.24 \\
$\mathrm{Indeno}$ & 0.54 & 0.90 \\
$\mathrm{D}[a e] \mathrm{P}$ & 0.07 & 0.12 \\
$\mathrm{D}[a i] \mathrm{P}$ & 0.10 & 0.25 \\
$\mathrm{D}[a h] \mathrm{P}$ & 0.76 & 0.96 \\
\hline $\mathrm{B}[a] \mathrm{A}: b e n$
\end{tabular}

$\mathrm{B}[a] \mathrm{A}$ : benzo $[a]$ anthracene; Chy: chrysene; $5 \mathrm{MeChy:} \mathrm{5-methylchrysene;}$ $\mathrm{B}[j] \mathrm{F}$ : benzo[j]fluoranthene; $\mathrm{B}[b] \mathrm{F}$ : benzo $[b]$ fluoranthene; $\mathrm{B}[k] \mathrm{F}$ : benzo $[k]$ fluoranthene; $\mathrm{B}[a] \mathrm{P}$ : benzo $[a]$ pyrene; $\mathrm{D}[a l] \mathrm{P}$ : dibenzo $[a, l]$ pyrene; $\mathrm{D}[a h] \mathrm{A}$ : dibenzo $[a, h]$ anthracene; indeno: indeno[ $[1,2,3-c d]$ pyrene; $\mathrm{D}[a e] \mathrm{P}$ : dibenzo[a,e $]$ pyrene; $\mathrm{D}[a i] \mathrm{P}$ : dibenzo $[a, i]$ pyrene; $\mathrm{D}[a h] \mathrm{P}:$ dibenzo $[a, h]$ pyrene; LOD and LOQ in $\mu \mathrm{g} \mathrm{kg}^{-1}$. 